\title{
PENINGKATAN KAPASITAS PRODUKSI BROWNIES SAYUR DAN PANGGANG PADA UKM RUMAH TERONG DAN SABRINA DI MALANG RAYA
}

\author{
Increasing Production Capacity Vegetable and Baked Brownies at SMFE Rumah Terong \\ and Sabrina, in Malang Raya \\ Kgs Ahmadi ${ }^{1)}$ dan Edyson ${ }^{2)}$ \\ ${ }^{1)}$ Program Studi Teknologi Industri Pertanian, Universitas Tribhuwana Tunggadewi Malang \\ ${ }^{2)}$ Program Studi Agroteknologi, Universitas Tribhuwana Tunggadewi, Malang \\ Email:kgs.ahmadi@yahoo.com
}

\begin{abstract}
Brownies processed foods originally made from the main raw chocolate. Then developed from various varieties of raw materials. In the market now known there are two types of brownies are steamed brownies and roasted brwonies. Both brownies produced by two different SMEs namely SME Rumah Terong for vegetable brwonies (steamed) and SME Sabrina produce brownies roasted. The face problem by both SMEs is low production capacity. Introduction of mixer and oven have been done on both partners. The result was an increase in the production capacity of SME Rumah Terong from $7.5 \mathrm{~kg}$ of flour to $10.5 \mathrm{~kg}$ on SME Sabrina there was a production increase from 12 to $16 \mathrm{~kg}$ of flour.
\end{abstract}

Key words: Steamed brownies, rumah terong, roasted brownies

\begin{abstract}
ABSTRAK
Program ini bertujuan untuk melakukan pembinaaan dan pendampingan UKM brownies di Malang Raya. Di pasaran sekarang dikenal ada dua jenis brownies yaitu brownies kukus dan brwonies panggang. Kedua brownies ini diproduksi oleh 2 UKM yang berbeda yaitu UKM Rumah Terong untuk brwonies sayur (kukus) dan UKM Sabrina memproduksi brownies panggang. Permasalahan yang dihadapi kedua UKM adalah kapasitas produksi rendah. Telah dilakukan introduksi mixer dan oven pada kedua mitra. Hasilnya terjadi peningkatan kapasitas produksi pada UKM Rumah Terong dari 7,5 kg tepung menjadi 10,5 kg sebagai dasar penghitungan adonan sementara pada UKM Sabrina terjadi peneingkatan produksi dari 12 menjadi $16 \mathrm{~kg}$ tepung sebagai basis penghitungan adonan.
\end{abstract}

Kata kunci: Brownies sayur, rumah terong, brownies panggang

\section{PENDAHULUAN}

Brownies merupakan makanan olahan yang populer sejak tahun 2000 an. Makanan olahan ini cukup menarik minat masyarakat dan mempunyai prospek pemasaran yang baik dilihat dari posisi produk yang tetap bertahan walaupun bermunculan jenis rerotian (bakery) yang baru. Termasuk di Kota Malang dan
Batu, produk brownies mempunya pasar yang cukup baik. Hal ini yang mendorong dua usaha kecil dan menengah (UKM) yaitu "Rumah Terong" milik Ibu Avida Laily di Kota Batu dan "Sabrina" milik Bapak Arsyad Nur Amin di Kota Malang melakukan usaha produksi dan pemasaran brownies. Brownies yang dihasil-kan dan dipasarkan oleh UKM "Rumah Terong" adalah brownies sayur 
kukus dan panggang, sedangkan brownies yang diproduksi dan dipasarkan oleh UKM "Sabrina" adalah brownies panggang.

Brownies sayuran merupakan satusatunya brownies di Kota Batu yang menggunakan sayuran dalam formulasi produknya. Brownies jenis ini belum mempunyai pesaing dan mempunyai pangsa pasar konsumen yang peduli terhadap kesehatan. Kota Batu sebagai wilayah pertanian menghasilkan produk hortikultura dalam jumlah melimpah. Keunggulan sayuran selain kandungan serat pangannya, juga mengandung senyawa bioaktif seperti beta karoten dalam wortel sebanyak $6.000-$ $54.000 \mu \mathrm{g} / 100 \mathrm{~g}$ berfungsi sebagai antioksidan dan pencegah kanker (Sharma et al., 2012), kandungan likopen pada tomat 14,725 $\mathrm{mg} / \mathrm{mg} / \mathrm{kg}$ (Rahina et al., 2008)), kandungan betalain pada bit 14,7 $\mu \mathrm{g} / \mathrm{g}$ (Hung dan Duy, 2012), klorofil (sawi) senyawa yang dapat mengoptimalkan fungsi metabolik, sistem imunitas, detoksifikasi, meredakan radang (inflamatorik) dan menyeimbangkan sistem hormonal (Limantara, 2007), zeaxantin (jagung) baik untuk kesehatan mata (Cheng et al., 2005), dan terong mengandung senyawa flavonoid 14,34 mg/100 g yang berfungsi sebagai antioksidan (Madukwe et al., 2013; Asih et al., 2015). Keunggulan bioaktif tersebut adalah dapat mencegah berbagai penyakit degeneratif sehingga brownies sayuran juga merupakan brownies sehat. Penggunaan sayuran dalam formulasi brownies dari segi biaya menguntungkan karena harganya lebih murah. Brownies sayuran menggunakan sayuran dengan jumlah 1:1 terhadap terigu sehingga jumlah sayuran yang digunakan cukup banyak dan signifikan.

Permasalahan yang dihadapi mitra Usaha Mikro Brownies Sayuran dan Panggang sama yaitu terbatasnya kapasitas produksi karena keterbatasan peralatan mekanis yang dimiliki. Karena itu perlu dicarikan solusi agar kedua mitra usaha mikro tersebut dapat diatasi untuk memenuhi permintaan pasar. Tujuan dari kegiatan ini adalah untuk meningkatkan produksi dan kualitas produk brownies sayur dan panggang.

\section{METODE PELAKSANAAN}

\section{Tempat dan Waktu}

Introduksi dilakukan di 2 (dua) UKM, yaitu UKM Rumah Terong yang memproduksi Brownies Sayuran di Kota Batu dan UKM Sabrina yang memproduksi brownies panggang. Kegiatan berlangsung selam 8 bulan

\section{Introduksi Teknologi}

Introduksi teknologi dilakukan agar kedua mitra dapat meningkatkan produksi sehingga dapat memenuhi permintaan pasar. Keterbatasan peralatan diatasi dengan memberikan peralatan mekanis berupa mixer dan oven.

Proses alih teknologi pada proses produksi brownies sayur dan panggang dilakukan pelatihan dan pendampingan pada awal proses produksi. Hal ini dilakukan agar proses mekanisasi dapat berjalan baik dan berkesinambungan.

\section{HASIL DAN PEMBAHASAN}

Introduksi peralatan mekanis pada proses produksi brownies sayuran dan panggang bertujuan untuk meningkatkan produksi dan kualitas brownies yang dihasilkan. Penerapan teknologi baru melalui mekanisasi proses meningkatkan efisiensi dan efektivitas proses produksi brownies. Karena itu yang menjadi sasaran program diterapkannya teknologi untuk meningkatkan kapasitas dan kecepatan produksi. Manurut Bunch (2001) suatu inovasi diharapkan dapat meningkatkan produksitivitas dalam suatu sistem bila inovasi tersebut dapat mengatasi faktor-faktor yang terdapat dalam sistem tersebut. 
Menurut Sukartawi (1988) semakian mudah teknologi itu dipraktekkan maka makin cepat pula proses adopsi teknologi tersebut. Karena itu agar proses adopsi dapat berjalan cepat maka pengujian inovasi harus lebih sederhana.

Peningkatan produksi stik fungsional lidah buaya dilakukan dengan introduksi alat pencampur (mixer) berkapasitas $5 \mathrm{~kg}$. Selama ini pencampuran adonan dilakukan secara manual dengan cara mengulen. Pengulenan dilakukan sampai adonan kalis dengan maksimal produksi $2 \mathrm{~kg}$ Dengan cara manual kapasitas produksi terbatas dan memakan waktu yang lebih lama. Sumber energi yang digunakan adalah energi listrik.

Introduksi alat pencampur (mixer) dapat meningkatkan kapasitas produksi dan proses berjalan lebih cepat . Kapasitas mixer yang diintroduksikan sebesar $5 \mathrm{~kg}$ (Gambar 1). Hal ini meningkatkan produksi brownies sayur dari $7,5 \mathrm{~kg}$ menjadi $10,5 \mathrm{~kg}$. Sedangkan pada UKM Sabrina terjadi peningkatan produksi dari $12 \mathrm{~kg}$ menjadi $16 \mathrm{~kg}$ tepung.
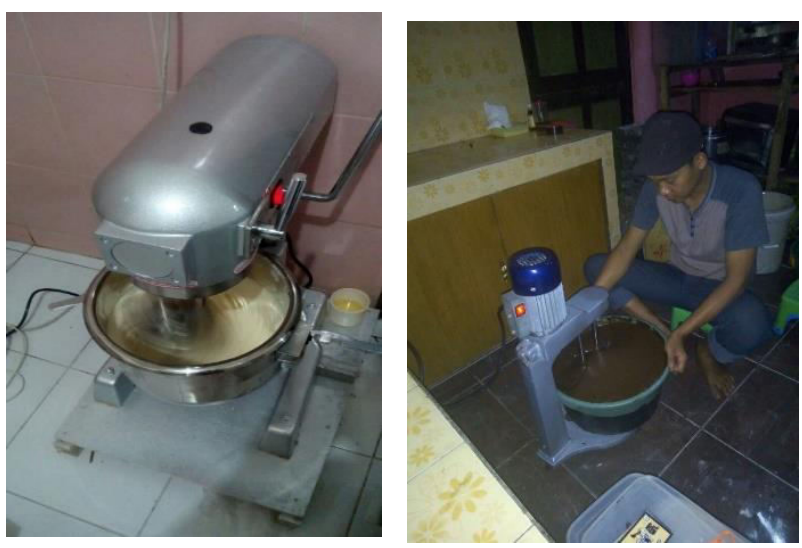

a. Mixer planetary

b. mixer dua pengaduk
Gambar 1. Jenis mixer

Penggunaan peralatan pencampur (mixer) memudahkan dalam pencampuran dan pencampuran bahan membutuhkan waktu yang lebih singkat. Selain itu pencampuran bahan adonan menjadi merata sempurna. Hal ini meningkatkan kualitas produk akhir yang dihasilkan.
Mixer yang digunakan pada UKM Rumah Terong dengan tipe yang sama (Gambar 1a), hanya dengan kapasitas yang lebih besar. Hal ini menyebabkan terjadinya peningkatan kapasitas produksi.

Sementara itu pada UKM Sabrina mixer yang digunakan selama ini adalah mixer rakitan sendiri hasil modifikasi dari alat pengebor yang biasa digunakan tukang. Pada ujung pemutar dipasang alat pengaduk (Gambar 2). Hal ini menyebabkan pekerjaan menjadi lebih berat karena alat tidak mempunyai tumpuan. Akibatnya proses produksi juga menjadi terbatas. Introduksi mixer dengan dua batang pengaduk meningkatkan kapasitas produksi dan kualitas brownies. Selain itu kerja lat ini lebih handal dengan kebutuhan listrik yang lebih rendah dan tidak bising.

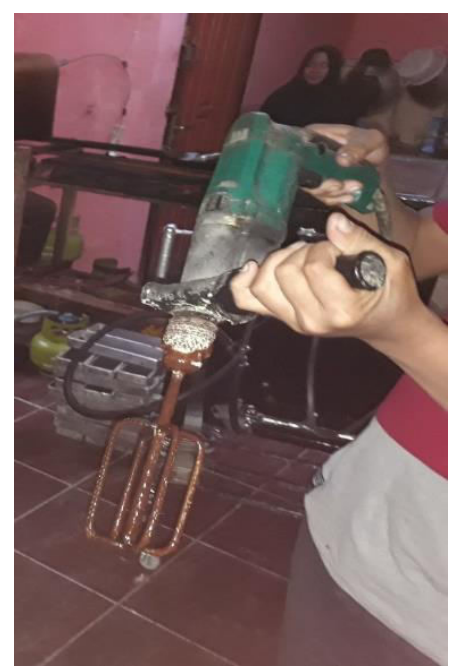

Gambar 2. Mixer rakitan

Peningkatan kapasitas produksi tidak hanya dengan pengadaan alat pengadon tetapi juga diperlukan peralatan pemanggang yang lebih besar. Saat ini Mitra 2 memiliki 6 unit oven sederhana dengan kapasitas tiap oven 6 loyang (Gambar 3). Sistem pemanggangan yang digunakan dengan oven ini hanya berasal api kompor dari bawah. Hal ini menyebabkan pemanggangan menjadi lama karena pemanasan yang tidak merata. Hal ini berpengaruh terhadap kapasitas produksi. 


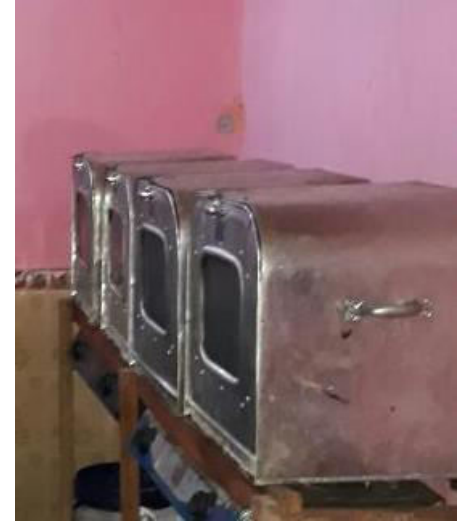

Gambar 3. Alat pemanggang (oven)

Sebagai bagian dari upaya peningkatan kapasitas produksi Mitra 2 maka dilakukan introduksi peralatan pemanggangan berupa oven. Oven ini mempunyai kapasitas sebesar 12 buah loyang yang berarti 2 kali lebih bersar dari oven yang biasa digunakan (Gambar 21). Sistem pengapian oven jika ini dari atas dan bawah. Sistem pengapian yang seperti ini akan memberikan pemanasan yang lebih merata sehingga pematangan lebih seragam. Selain itu dengan sistem pengapian yang berasal dari atas dan bawah ini akan mempercepat proses pematangan. Karena itu introduksi oven ini diharapkan dapat meningkatkan kapasitas produksi dan mempercepat proses produksi.

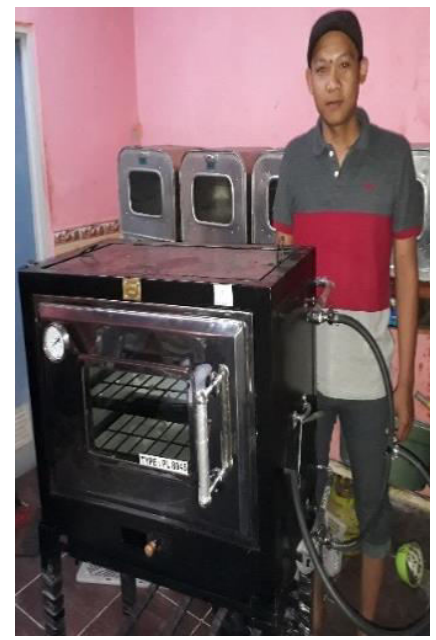

Gambar 4. Oven kapasitas 12 loyang
Hasil uji coba penggunaan oven dengan sistem pengapian atas bawah ini menunjukkan penggunaan gas yang lebih efisien. Pada oven yang lama untuk 2 loyang maka harus menggunakan 2 kompor secara bersamaan. Dengan cara ini makan jumlah gas yang digunakan akan lebih banyak dan boros.

\section{KESIMPULAN}

Introduksi alat pengaduk dan oven pada UKM Rumah Terong meningkatkan produksi dari $7,5 \mathrm{~kg}$ tepung menjadi $10,5 \mathrm{~kg}$ tepung, sedangkan pada UKM Sabrina introduksi alat pengaduk (mixer) meningkatkan produksi dari 12 menjadi $16 \mathrm{~kg}$ tepung.

\section{UCAPAN TERIMA KASIH}

Ucapan terima kasih disampakan kepada Direktorat Riset dan Pengabdian Masyarakat Direktorat Jenderal Penguatan Riset dan Pengembangan, Kemristekdikti yang telah membiayai kegiatan IbM ini melalui DIPA Kopertis VII dengan Surat Perjanjian Penugasan Pelaksanaan Program Pengabdian kepada Masyarakat Nomor: 258/SP2H/PPM/DRPM/II/2017, tanggal 03 April 2017.

\section{DAFTAR PUSTAKA}

Bunch, R. (2001). Dua Tongkol Jagung: Pedoman Pengembangan Pertanian Berpangkal Pada Rakyat. Ed II. Yayasan Obor Indonesia, Jakarta.

Limantara L. (2006). Mujarab Bagi DB dan Kanker http://impossible.blog.m3access.com/posts/cat_1_TanpaKategori. html. 10 Mei 2016.

Madukwe, E.U., Nwabunze, A.M., and Onyibalu, C.L. (2013). Bioavailability of selected phytochemical in the 
extracts of fluted pumpkin (Telfairi accidentalis), tomoto (Lycopersicum escelentum) and eggplant (Solanum melongena). International Journal ofBasic and Applied Sciences 2(3): 251257.

Malang Times. (2014). 3,5 Juta Wisatawan Kunjungi Batu. http://malangtimes.com/wisata/0811201 4/15522/35-juta-wisatawan-kunjungibatu. html. Diakses 20 Maret 2015.

Pokorny J. (2002). Frying. In: Henry CJK, Chapman $\mathrm{C}$ (eds) The nutrition handbook for ood processors. CRC Press, New York.

Rahina, A., Maimunah, dan Yosita L. (2008). Penentuan Aktivitas Antioksidan, Kadar Fenolat Total dan Likopen pada Buah Tomat (Solanum lycopersicum L). Jurnal Sains dan Teknologi Farmasi 13(1): 31-37.
Sa'nchez-Gimeno AC, Negueruela AI, Benito M, Vercet A, Oria R. (2008). Some physical changes in Bajo Arago'n extra virgin olive oil during the frying process. Food Chem 110:654-658.

Sahin, S. and S.G. Sumnu. (2009). Advances in Deep-Fat Frying of Foods. CRC Press. Neww York.

Sharma, K.D., S. Karki, N.S. Thakur, and S. Attri. (2012). Chemical composition, functional properties and processing of carrot. A review. J Food Sci Technol 49(1):22-32.

Soekartawi. (1988). Prinsip Dasar: Komunikasi Pertanian. UI Press. Jakarta.

UKM-Jatimnet. (2014). Pemkot Batu Dorong UMKM. http://ukmjatim.net/pemkot-batudorong-usaha-handycraft-daripadamakanan-dan-minuman/. Diakses 20 Maret 2015. 